\title{
LITERATURA NA ERA DO DIGITAL
}

\section{LITERATURE IN THE DIGITAL ERA}

\author{
Rogério Lima*
}

RESUMO: Este trabalho desenvolve reflexões básicas concernentes aos problemas advindos das relações entre a literatura e as transformações tecnológicas. Investiga também uma conseqüente mudança da sensibilidade estética, operada pela técnica, no campo da arte. Neste final de século, deparamo-nos com uma série de problemas que questionam o futuro da arte e, em particular, o destino da literatura. À medida que ingressamos no mundo virtual, conhecido como ciberespaço, as formas tradicionais de representação passaram a experimentar abalos imprevisíveis. Transformações estéticas e técnicas já foram experimentadas antes, mas não de forma tão radical quanto ao que se processou ao longo da segunda metade do século XX.

PALAVRAS-CHAVE: Literatura, transformações tecnológicas, mudança da sensibilidade estética, cibercultura.

ABSTRACT: This analysis purports to develop some basic notions concerning the issues brought about by the relationship between literature and technological transformations. It also addresses the changes effected by technological advancement in the field of aesthetics and aesthetic sensibility, as evinced by a series of problems which, as of the end of last century, pose questions relating to the future of art and, particularly, the fate of literature. As we cross into the virtual world, a.k.a. "cyberspace," traditional forms of representation are shattered by unpredictables mutations. Even though aesthetic changes and techniques have been experienced before, nothing that happened earlier can approach ever so gently the radical transformations that took place along the second half of the $20^{\text {th }}$ century.

KEYWORDS: Literature, technological transformations, aesthetics, aesthetic sensibility, cyberculture.

\footnotetext{
* Professor do Departamento de Teoria Literária e Literaturas da Universidade de Brasília - UnB. Doutor em Semiologia Pela Faculdade de Letras da Universidade Federal do Rio de Janeiro - UFRJ, ex-presidente da ANPOLL, autor dos livros O dado e o óbvio: a significação do romance na pós-modernidade e O imaginário da cidade.rlima@unb.br
} 
Há um quadro de Klee, que se chama Ângelus Novus. Representa um anjo que parece afastar-se de algo que ele encara fixamente. Seus olhos estão escancarados, sua boca dilatada, suas asas abertas. O anjo da história deve ter esse aspecto. Seu rosto está dirigido para o passado. Onde nós vemos uma cadeia de acontecimentos, ele vê uma catástrofe única, que acumula incansavelmente ruína sobre ruína e as dispersa a nossos pés. Ele gostaria de deter-se para acordar os mortos e juntar os fragmentos. Mas uma tempestade sopra do paraíso e prende-se em suas asas com tanta força que ele não pode mais fechá-las. Essa tempestade o impele irresistivelmente para o futuro, ao qual ele vira as costas, enquanto o amontoado de ruínas cresce até o céu. Essa tempestade é o que chamamos progresso.

Walter Benjamin ${ }^{1}$

\section{A CRÍTICA NA ERA DO DIGITAL}

Roland Barthes, ao analisar o Noveau Roman, ressaltou, como característica do tempo em que vivemos, o fato de, à época, a nossa sociedade ser particularmente difícil de compreender. O homem se vê quase impossibilitado de analisar. Vivenciamos uma situação de ambigüidade, ao mesmo tempo, vivemos numa sociedade de classes e de massas. Os grandes problemas da sociedade se apresentam de forma embaralhada. A própria cultura política aparece como marca de um tempo de estagnação. Como não poderia deixar de ser, esses fatores díspares influenciam a escrita $\mathrm{e}$ nela se traduzem (BARTHES, 1982). Desta forma, identificamos na escrita a arte de levantar questões e não de responder a elas, ou de as resolver. Assim como o romance modernista produziu essa consciência de que a literatura era forma de levantar questões, entendemos que o romance pósmoderno também a tenha desenvolvido e, conseqüentemente, todo esse questionamento se desenvolveu no âmbito da crítica literária.

\footnotetext{
${ }^{1}$ Benjamin, Walter. "Sobre o conceito da história" in Benjamin, Walter. Magia e técnica, arte e política: Ensaios sobre literatura e história da cultura. Tradução: Sérgio Paulo Rouanet. Prefácio: Jeanne Marie Gagnebin. 4ª ed. São Paulo: Brasiliense, 1985. P. 226.
} 
A crítica tem sido uma atividade exercida e respeitada. Porém, ao falarmos de "Crítica" na pós-modernidade corremos o risco de o assunto ter se tornado um tema antiquado e de certa forma ocioso. Para Terry Eagleton, a crítica perdeu toda a relevância social, passando a fazer parte do ramo das relações públicas da indústria literária, ou passou a ser uma questão totalmente interna às academias (EAGLETON, 1991: 1). De fato isto nem sempre aconteceu e nem é necessário que aconteça.

Segundo Leyla Perrone-Moisés - crítica do pós-modernismo - em tempos pós-modernos a crítica se encontra relegada ao rápido resenhismo de jornais, "necessário, mas não suficiente" (PERRONE-MOISÉS, 1996). A crítica ao resenhismo de jornais não é fato novo, pois o escritor Henry James já chamava a atenção dos seus leitores, na virada do século XIX para o século XX, sobre esse fenômeno que adquirira grande força e penetração advinda da modernização da imprensa e das transformações que ocorriam, provocadas pelo processo de industrialização crescente. Na opinião de James resenha e crítica não têm nada a ver uma com a outra. A resenha unida ao que ele chamou de "nosso maravilhoso sistema de publicidade" engendraram um grande espetáculo tosco que arrastava os leitores impedindo que eles tivessem olhos para uma análise mais aprofundada dos textos literários.

(...) A imprensa é uma vasta boca aberta que tem de ser periodicamente alimentada - um vaso de enorme capacidade que tem que ser preenchido. É como um trem regular que sai numa hora marcada, mas que só pode sair se todos os lugares estiverem ocupados. Os lugares são muitos, o trem é consideravelmente longo, e daí a fabricação de bonecos para as estações em que não há passageiros suficientes. Um manequim é colocado no assento vazio onde passa por uma figura real até o final da jornada. Parece-se bastante com um passageiro, e você só percebe que ele não o é quando nota que não fala nem se move. O guarda vai até ele quando o trem pára, limpa as cinzas de sua face de madeira e muda a posição de seu cotovelo, de modo que sirva para uma nova viagem. Da mesma forma, num jornal bem conduzido, os blocos de remplissage são os bonecos da crítica - os pontos regulamentes vazios da maré da conversa. (JAMES, 1995: 47-48)

James vislumbrava um futuro não muito promissor para a crítica, pois, na sua opinião, com os avanços da imprensa a resenha apresentava uma saúde crescente, inabalável e "muitas das características que seduzem alguém a render uma homenagem involuntária às bem-sucedidas empreitadas" (JAMES, 1995: 48). 
Segundo Perrone-Moisés, a situação na qual foi posta a literatura na pósmodernidade configurou-a como mera depositária da memória cultural. Essa situação detectada pela autora levou-a a elaborar algumas questões acerca desse reposicionamento da literatura:

Quais são exatamente os fenômenos culturais preservados na e por meio da literatura? A literatura é, às vezes, freqüentemente ou sempre um meio de promover a tradição, a continuidade, ou mesmo a permanência? Isso é uma boa coisa? Ou seria, pelo contrário, uma razão para pôr em causa a literatura (e/ou a estética em geral)? (PERRONE-MOISÉS, 1996)

Perrone-Moisés chama atenção para o fato de que considerada apenas como memória a literatura fica presa a palavras como "depositária", "preservação", "tradição", "continuidade", "permanência" e é lançada num imobilismo e num conservadorismo que nunca havia conhecido. Este tipo de classificação gera um esvaziamento que coloca em risco a literatura enquanto produtora de conhecimento, de crítica do real e "proposta indireta (estética) de alternativas para o mesmo".

Temos uma visão diferente a respeito do pós-moderno (LIMA, 1998). Pois, apesar de sofrer diversas críticas, uma delas é a de instaurar um valetudo, o pós-moderno na realidade procura reavaliar o conceito de arte, rompendo com padrões tacitamente aceitos. O pós-moderno não sofre da angústia da influência, pelo contrário, ele a celebra e a expõe sobre um novo ponto-de-vista. Não há uma ameaça ao Cânone, mas justamente uma celebração do mesmo. Ítalo Calvino lembra da necessidade de se ler os clássicos como forma de construção de um novo conhecimento, e não como caminho para uma erudição diletante (CALVINO, 2000).

A crítica pós-moderna no Brasil, ainda em formação, precisa se debruçar sobre a tarefa do estabelecimento de uma teoria literária que busque criar condições para a compreensão das transformações pelas quais tem passado a literatura brasileira, e não só ela, mas a literatura do ocidente como um todo, desde o século XIX. Na realidade, ela, a crítica pós-moderna, é um trabalho de reinterpretação da própria crítica, uma crítica da crítica. O que essa crítica da crítica tem por objetivo é restabelecer a idéia da literatura como forma de conhecimento, exercício da liberdade, crítica do real, mito verdadeiro, utopia, projeto. E se recolocar como diálogo, ampliação da leitura, extensão do saber e da ação da obra.

Este processo estabelecido pela crítica pós-moderna recoloca na ordem das discussões o discurso teórico como produto da reflexão crítica. É 
importante lembrar que quando uma comunidade não tem o hábito da discussão, a utilização da linguagem crítica sempre lhe parecerá ameaçador (LIMA, 1981: 193). Pela sua própria natureza o discurso teórico gera alguns questionamentos e dificuldades. A crítica pós-moderna cria um grande incômodo ao propor um redimensionamento dos objetivos dos estudos literários e da própria função da crítica. É a crítica se debruçando sobre ela própria com o intuito de construir o seu caminho, reproblematizando a sua função, virtualizando os seus objetivos em meio ao paradoxo da pósmodernidade.

É preciso que se compreenda que a arte pós-moderna tem como uma de suas características contestar de maneira aberta e franca princípios como valor, ordem, sentido, controle e identidade, que são constituintes das premissas básicas do humanismo liberal. Esses princípios que direcionam o liberalismo burguês ainda desempenham um papel em nossa cultura, porém já não são mais encarados como eternos e imutáveis.

Os paradoxos da teoria pós-moderna e de sua prática posicionam-se no interior do sistema e mesmo assim agem com o objetivo de possibilitar que as premissas desse sistema sejam consideradas como ficções ou como estruturas ideológicas. Isso não invalida o seu valor de "verdade", mas determina as condições dessa "verdade". Esse tipo de processo revela os percursos dos sistemas significantes que constituem nosso mundo - um mundo formado por sistemas construídos com a finalidade de atender às nossas necessidades.

\section{PROTOCOLOS CRÍTICOS: O TEXTO DA ERA DIGITAL}

Alguns segmentos da crítica literária não vêm como falar de literatura sem tocar no tema tecnologia e avanço tecnológico na área da produção editorial (PÉCORA, 2000: 15). Na sua grande maioria os artigos que tocam no assunto relatam as mudanças radicais ocorridas neste setor decorrentes da proliferação de computadores, cada vez mais poderosos, e programas de editoração que tornam possível fazer em casa ou em pequenos escritórios o que antes só era possível a uma equipe de técnicos e a um parque de máquinas grandes e complicadas de operar (TALENS, 1994).

Estas mudanças se revelam perfeitas no atendimento de demandas segmentadas, decorrentes das transformações sofridas pela sociedade e pela segmentação dos mercados, com a publicação de textos de interesse específico para determinados grupos ou comunidades. É difícil que não haja um acompanhamento por parte de produtores culturais brasileiros do 
que já se tornou evidente em outros países com maior volume de produção cultural: a renovação do interesse por gêneros e literaturas regionais; a implementação de produção de literaturas geracionais, em geral aglutinadas em torno de revistas urbanas (rappers, clubers, ciberpunks) e a continuidade de literaturas das chamadas minorias sexuais (gays, lésbicas etc).

No que diz respeito aos aspectos formais é possível ressaltar o fato de todos os segmentos terem em comum um tratamento não exaustivo da matéria quelhes cabe, enfocada de umângulo parcial epessoal, evidenciando um tratamento marcadamente afetivo; uma anarquia de gêneros, em que um romance pode ser composto por diversas formas e artefatos de comunicação: manifestos, volantes de rua, textos de comerciais, trechos de prosa poética, álbum de fotografias, desenhos etc. O que nos possibilita ler a literatura produzida por essa mediação tecnológica intensa como um segmento da literatura pós-moderna. Esse tipo de manifestação cultural e artística não ocorre somente no âmbito da literatura, mas também em diversos segmentos das artes: música, artes plásticas (ciberarte) etc.

Partindo deste ponto de vista, é possível afirmar que uma verdadeira implosão assola as formas realistas de narrativa baseadas na descrição de um modelo teórico totalizante da história, e ganham espaço e poder as narrativas que são, ao mesmo tempo, explicitamente artificiosas e restritivamente associadas a experiências vividas, não teorizadas ou transformadas em idéias. Como exemplo desse tipo de narrativa é possível citar o romance de Valêncio Xavier, O Mez da gripe (1998), construído a partir de recortes de jornais, reproblematizando a forma narrativa do romance. Outra obra que podemos citar, relacionada às experiências de colagem diversas, é o ciberomance de Fausto Fawcett, Santa Clara Poltergeist (S/D), que apresenta influências nítidas de William Gibson e Donald Barthelme e antecipa em alguns anos a visão que teríamos das comunidades multiculturais que vivem nas grandes metrópoles, por intermédio dos filmes de Wayne Wang e Paul Auster.

A inovação do romance de Fawcett se dá a partir da mistura que ele produz ao narrar o submundo da cidade do Rio de Janeiro, mais especificamente o submundo do bairro carioca de Copacabana. A religiosidade do povo; o avanço das novas tecnologias que começavam a se popularizar; efeitos paranormais; energia nuclear; erotismo e intrigas financeiras internacionais compõem a matéria da ficção fawcettiana. Toda a narrativa se realiza fazendo uso da linguagem musical do rap. Em Santa Clara Poltergeist, Fawcett apresenta em seu primeiro romance, ainda que a crítica apresente 
grande resistência à sua obra, uma forma particular de encarar a cidade, ele a vê como o lugar onde se encena o drama urbano, sujeito a todo tipo de mediação, e os acontecimentos do mundo que a cerca.

Copacabana é, possivelmente, um dos mais famosos bairros do mundo, espécie delugar-ícone da cultura brasileira, que já foi personagem de filmes de ficção (Copacabana me engana, de Antônio Carlos Fontoura) documentários (Opinião Pública, de Arnaldo Jabor, Copa Mista, de José Joffily). O bairro, o mais populoso do Rio de Janeiro, é uma espécie de Brooklyn carioca, nele encontramos todos os tipos de brasileiros, estrangeiros, religiões, formas de viver e sonhar a cidade do Rio de Janeiro. Bairro decadente, entupido carros e ônibus, imenso corredor de passagem para outros bairros da zona sul do Rio de Janeiro. Nas suas ruas encontramos os legítimos representantes da sua decadência: prostitutas, ambulantes (representantes do comércio informal), traficantes, menores abandonados (representantes do fracasso da ação social do Estado), trombadinhas, assaltantes (representantes da falência da segurança pública), comerciantes e moradores que convivem, se não em harmonia, pelo menos respeitando minimamente espaços delimitados de forma bastante precária, pois a cada instante há sempre a possibilidade de quebra dos limites sempre muito tênues.

É nesse espaço que Fawcett ambienta o seu ciberomance, ou melhor, a sua cibernarrativa ou ciber-rap-literário. Fawcett cria uma Copacabana infernal, bastante diferente de a princesinha do mar cantada por Dick Farney, no embalo da Bossa Nova. Longe do lirismo romântico da Bossa Nova e imersa no Rap caótico fawcettiano, surge uma Copacabana assustadora, um território off, que nos faz lembrar a cidade de Nova York no filme fuga de Nova York, do cineasta norte-americano John Carpenter. Esse bairro de Copacabana infernal é habitado por personagens incomuns na literatura brasileira, mas bastante comuns da cultura urbana nacional e do universo fawcettiano: a loura striper e dançarina de boate, o negro tecno-especialista, mulatas, sexo, televisão, religião, violência, tecnologia e cultura pop.

Copacabana é o território do exercício pop narrativo de Fawcett. Tanto nas letras de seus raps como no seu ciberomance o bairro é esquadrinhado juntamente com os seus personagens, como a chinesa videomaker, a prostituta Tânia Miriam, amiga de Verinha Blumenau, ou Kátia Flávia certamente o personagem mais famoso já criado por Fausto Fawcett. Para o leitor-ouvinte de seu rap-narrativo é possível acompanhar o percurso das personagens por zonas do bairro, assim como o escritor Machado de Assis fez com seus personagens ao circularem pela cidade do Rio de Janeiro em 
sua literatura e como o narrador do conto $A$ arte de andar nas ruas do Rio, de Rubem Fonseca (1998).

Os personagens de Fawcett não circulam pelas ruas da cidade, mas do bairro de Copacabana, fragmento aglutinador, senão de todas, pelo menos de boa parcela das diversas manifestações sociais e culturais que a cidade apresenta. Narrar Copacabana talvez seja tão ou mais complexo que narrar a cidade em sua totalidade, se é que isso possa ser possível, pois Copacabana concentra em um único e pequeno espaço territorial todos os problemas encontrados em cidades médias brasileiras: superpopulação, falta de espaço para crescer, marginalidade, tráfego intenso e saturado, sujeira etc.

Achamos ser impossível narrar a cidade moderna. Para Néstor Garcia Canclini a cidade se configura hoje como um grande videoclipe onde é possível constatar a convivência de diversos lugares do mundo ao mesmo tempo, formando um grande mosaico cultural; assim é em Nova York, o bairro do Brooklyn; a Cidade do México, onde é possível encontrar quase todos os lugares da América Latina (CANCLINI, 1997). A grande questão que se instaura nesse momento é a de como narrar ou realizar a enumeração desse conjunto infinito que é a cidade moderna.

Um fato curioso entre os moradores do Rio de Janeiro, principalmente entre os moradores da zona sul, área da cidade econômica e financeiramente mais privilegiada, apesar das contradições de várias ordens, é a pouca mobilidade existente entre um ponto e outro da cidade. É possível que esse fato tenha sido preponderante na construção do imaginário fawcettiano.

O outro ponto forte da narrativa de Fausto Fawcett é a sua linguagem que mescla diversos elementos: religiosidade, sexualidade, eroticidade, televisão, linguagem de telejornais, amor ao pop, referências literárias e até mesmo críticas à cultura de massa.

O romance de Fausto Fawcett é o que poderíamos chamar de narrativavideoclipe, na qual o leitor encontra um gosto do narrador pelo fragmento e pelo detalhe, às vezes excessivo, um verdadeiro saque narrativo à cultura carioca e mundial, numa montagem efervescente de imagens caóticas e descontínuas. A cidade do Rio de Janeiro no romance de Fawcett não tem um foco organizador, pois ela está em todos os lugares e não está plenamente em lugar nenhum. A cidade em Santa Clara Poltergeist é o território da desordem, a virtualização da ordem, não potencialidade, mas como problematização. A temperatura da cidade é alta e isso estimula o narrador Fawcettiano a chamá-la de cidade maravilha da beleza e do caos, cenário de espetáculos narrativos urbanos amplamente divulgados pela 
mídia. Cidade onde os habitantes, sobreviventes de episódios trágicos, encarnam novos papéis em outras histórias igualmente trágicas, ora como protagonistas, ora como reféns da violência urbana, e morrem mil vezes pelas mãos da polícia em replays televisivos. ${ }^{2}$ Este é o único momento em que os meios de comunicação narram os fatos produzidos pela cidade de forma continua, sem cortes, música ou montagem vertiginosa, e sem esses elementos de efeito narrativo os fatos se revelam monótonos, angustiantes e culminam com um desfecho geralmente trágico.

$\mathrm{O}$ romance pós-moderno possui uma grande tendência em se aproximar do popular, buscando com isso a aceitação do grande público; há uma valorização do paraliterário; o texto é construído sobre uma intertextualidade infinita. $\mathrm{O}$ texto pode até se transformar em metáfora do livro que o enforma, como é o caso de O Nome da Rosa, de Umberto Eco, o texto clássico da literatura pós-moderna.

O pós-modernismo incorpora todos os elementos da literatura modernista - numa evidente intensificação do ludismo na criação literária - envolvido por um espírito de subversão e anarquia cultural. A linguagem, de todos os elementos da literatura modernista, é o que recebe maiores privilégios: a literatura passa a ocupar-se mais de si, do fazer da obra, do que dos conteúdos de vida que possa dar a conhecer. O mundo circundante assume, a partir de então, o papel de coadjuvante. Concomitantemente, a literatura do pós-modernismo torna-se menos fechada que a modernista, voltando-se para um público mais eclético. O seu interesse também é eclético, variando de Balzac a Joyce, há ainda a característica alegórica dessa literatura que é apontada por vários teóricos, em contraposição à literatura fundada no conceito clássico-romântico de símbolo. Por outro lado, esse tipo de manifestação revela, no que classificamos como literatura pós-moderna, uma tendência ao fragmento, ao descontínuo, à polissemia, características atribuídas à alegoria por Walter Benjamim. Estas características colocam a literatura pós-moderna em oposição às literaturas clássicas e modernas, que estão centradas na estética do símbolo. Isto implica: uma captação do

\footnotetext{
${ }^{2}$ Referimo-nos ao caso de Sandro do Nascimento, sobrevivente da chacina da Candelária, protagonizada por policiais militares, que anos depois tomaria, em um assalto, os passageiros de um ônibus de transporte coletivo da linha 174, no Rio de Janeiro, como seus reféns durante horas. A tragédia culminou com a morte de uma refém, no momento em que $o$ assaltante se entregaria e com a sua morte quando era levado, imobilizado, para um hospital da cidade, aparentemente sem nenhum ferimento.
} 
todo no particular, a coincidência entre o sujeito e o objeto, a harmonia entre o homem e a natureza; um efeito comunicativo direto, que prescinde de comentário decifrador; o amor ao aspecto sensível, concreto, do representado e a revelação de algo em última análise inexprimível, pois o símbolo, por mais significativo que nos pareça, contém sempre uma inesgotável reserva de sentido (MERQUIOR, 1969: 105).

A estética do símbolo seria totalizadora, harmônica, contínua e representa uma unidade de uma intencionalidade significante e de uma significação objetiva (ROUANET, 1989: 256). José Guilherme Merquior defende a tese de que se conforma no texto literário pós-moderno uma figuração alegórica de tipo hiper-real e metonímico, enquanto no texto modernista a alegoria se configurava como metafórica e surreal. Como exemplo de alegorias metafóricas cita as produzidas por Kafka e pelos surrealistas, daí o seu caráter enigmático, enquanto as alegorias produzidas por Borges e Beckett não têm esse caráter, o que poderia estabelecer uma diferenciação entre Kafka e Borges. A crítica, na virada do século XX para o XXI, fala de uma nova forma de romantismo baseado neste aspecto que a literatura apresenta. Pelo viés da facilidade que o uso do computador introduziu na criação artística, a crítica aponta para o fenômeno de a exuberância técnica se tornar o sustentáculo dos novos repertórios da invenção literária.

A argumentação acerca do cotidiano pós-moderno advoga que ele seria qualitativamente diferente do moderno; essa diferença estaria expressa através de características que vão da estetização da mercadoria à extinção dos espaços de intimidade, passando pela predominância da informação, substituição do livro pelo vídeo, pelo hedonismo, consumismo generalizado e uma estrutura psíquica marcada simultaneamente por um intenso narcisismo e por um total esvaziamento da subjetividade. Essas características transmitem uma forte sensação de déjà $v u$. Essa sensação é justificada pela familiaridade desses traços que correspondem, como avaliação crítica ou como elogio, à descrição da modernidade elaborada pela própria modernidade.

\section{PERTO DA MÁQUINA}

A obsessão pela tecnologia é uma manifestação; não há nenhuma diferença entre a fascinação (ou horror) atual pela informática e o deslumbramento (ou aversão) protomoderno pela máquina. A máquina, com o advento da modernidade estética, adquire um valor universal (SUBIRATS, 1991:23), passando a desempenhar, no início do século XX, o mesmo papel que a natureza no século XVIII, ou o gênio no período romântico. No 
contexto da modernidade estética a máquina adquire funções demiúrgicas, proféticas, messiânicas. Ela assume o lugar de verdadeiro sujeito da história. É dessa forma que Walter Benjamin, Fernand Léger, Le Corbusier, Picabia, Duchamp, Brecht a viveram. A máquina pode assumir também funções demoníacas, infernais e destrutivas. Fritz Lang em Metrópolis, obra cinematográfica do expressionismo alemão, vêa indústria como um Moloch, o deus tirano, ciumento, vingativo, sem pena, que exige de seus adoradores obediência até a morte, enquanto eram devorados por ele. Em o Golem, de Wegener, outro representante do expressionismo alemão, é mostrada a destrutividade imanente ao artifício tecnológico. Essa destrutividade é situada em terreno próximo à lenda hebréia do golem e às questões a ela relacionadas, como a busca da verdade e a morte de Deus.

Alguns autores afirmam não encontrar nenhum ponto de convencimento que leve a acreditar que a informatização da sociedade seja diferente da maquinização da vida vivenciada pelos modernos como uma graça ou uma desgraça. Argumenta-se que há, hoje, uma valorização exagerada e ingênua da capacidade da tecnologia de transformar a sociedade.

Tomando o capitalismo como exemplo da não-interferência maquínica nas estruturas da sociedade, a conclusão a que se chega é a de que não foi a máquina a vapor que deu início ao capitalismo, mas uma nova forma de relações sociais, e não será o computador de última geração que vai decretar o fim do capitalismo, mas a transformação econômica das relações sociais.

Resta saber como é que fica o consumismo, o narcisismo, o hedonismo e a transformação psíquica do indivíduo. É importante lembrar que foram descritos por Adorno, Marcuse e Horkheimer os processos de unidimensionalização das consciências, a modelagem do indivíduo pela publicidade epela indústria cultural, a erotização do mundo das mercadorias, o confisco da psicologia individual pelo todo, a dessublimação repressiva e todos os mecanismos que caracterizam a fetichização integral do mundo da cultura, sua subordinação absoluta ao valor de troca.

Caso haja a alegação de que a sociedade descrita pela escola de Frankfurt já não seja tipicamente moderna, a proposta é de que se recue aos primórdios da modernidade e se tome Tocqueville ou Stuart Mill como modelo e veremos que a descrição do rebanho humano imbecilizado pelo conformismo não difere em muito dos indivíduos pós-modernos, programados pela tecnociência eletrônica para terem os mesmos desejos e comprar as mesmas mercadorias. No cotidiano contemporâneo não há ruptura, o que há é uma veemência de características pré-existentes (ROUANET, 1989: 258-259). 
O processo da evolução técnica e a cidade, olugaronde, preferencialmente, a técnica é utilizada, se apresentam como bases dos novos repertórios da invenção literária, não só na sua forma de produção, mas principalmente na temática tratada pela literatura, sob formas tão díspares e de qualidades alternadas, no decorrer da segunda metade do século XIX e ao longo do século XX. Autores como: Edgard Alan Poe, O Jogador de Xadrez de Maetzel e O Homem da Multidão; E.T.A Hoffman, Os Autômatos; Emile Zola, Germinal; Eça de Queiroz, As Cidades e as Serras; Júlio Verne, Paris no Século XIX; Franz Kafka, A Metamorfose; romance no qual a máquina não aparece na sua figuração tradicional de artefato, mas está configurada na negação humana do homem na modernidade, através do processo de massificação e coisificação; Aldous Huxley, Admirável Mundo Novo; Herman Hesse, O Jogo das Contas de Vidro; Max Frisch, Homo Faber; J.G. Ballard, Crash: estranhos prazeres; Michel Houellebecq, Partículas Elementares; e outros tantos, ressaltam em suas narrativas, sob diferentes pontos de vista, as relações do homem com a técnica e suas relações com o mundo mediado por ela.

\section{NOVAS TÉCNICAS, GRANDES AUTORES?}

O processo de evolução técnica não é estável e tranqüilo, nem é possível afirmarqueirá produzirgrandesautoresouobrasliterariamentesignificativas. O que há de mais importante nesse processo é um movimento contra a corrente dos best sellers ou gêneros apelativos como o dos livros de autoajuda. Na contracorrente da recusa de teorias das formas literárias citadas, é possível indicarmos a afirmação do que pode ser identificado como nova ficção objetiva: o ensaio. Esse espaço está sendo ocupado pelo ensaio, pois "Nenhuma outra forma literária parece mais complexa do que ele em termos de impacto afetivo e intelectual" (PÉCORA, 2000). Isto não quer dizer que o ensaio nunca tenha estado presente na literatura. De forma geral, é possível identificar em diversos autores e textos ficcionais o exercício do ensaio. $\mathrm{O}$ romance de Thomas Mann, A montanha mágica, é um bom exemplo de texto ensaístico, sem deixar de ser pura ficção; acrescentaríamos ainda $O$ jogador de xadrez de maetzel (POE, 1981), talvez a primeira denúncia da técnica como artifício de entretenimento proporcionado pela máquina, e $O$ demônio da perversidade (POE, 1996), manifestação da recusa de perder o anúncio e a possibilidade de reconhecimento de "um grande feito" - ainda que criminoso - no anonimato da multidão, ambos textos de Edgar Alan Poe, que estão situados numa fronteira tênue e nebulosa, pois oscilam entre o ensaio teórico e a pura ficção. No romantismo brasileiro, detectamos em 
José de Alencar uma assumida determinação para a realização e a utilização do ensaio mesclado ao romance romântico:

Quando em 1848 revi nossa terra natal tive a idéia de aproveitar suas lendas e tradições em alguma obra literária. Já em São Paulo tinha começado uma biografia do Camarão. Sua mocidade, a amizade heróica que o ligava a Soares Moreno, a bravura e lealdade de Jacaúna aliado dos portugueses, e suas guerras contra o célebre Mel Redondo; aí estava o tema. Faltava-lhe o perfume que derrama sobre as paixões do homem e da mulher. Este livro é pois um ensaio ou antes uma amostra. ${ }^{3}$ Verás realizadas nele minhas idéias a respeito da literatura nacional; e achará aí poesia inteiramente brasileira, haurida na língua dos selvagens (ALENCAR, 1992: 86).

A detecção da presença do ensaio na literatura aponta para integração de uma liberdade maior à escritura do texto literário, pois o ensaio é o olhar penetrante presente no texto. "Liberdade de olhar; olhar da liberdade" (PORTELLA, 2000: 176).

É possível ir mais além nesta discussão acerca do ensaio como manifestação literária de prestígio intelectual, pois, por meio da análise crítica, detecta-se uma espécie de subgênero que transita entre o romance tradicional e o ensaio no romance A televisão, de Jean-Philippe Toussaint (1999). Fato semelhante é identificável em O videota, de Jerzy Kozinsk (1971).

Constantemente a televisão tem sido tema de grandes polêmicas e debates. Pierre Bourdieu publicou no Brasil um ensaio intitulado Sobre a Televisão (1997) abordando os aspectos de dominação e manipulação desse veículo de comunicação de massa. Porém, desde O Videota, não se tinha notícia de que o objeto televisão houvesse se transformado em assunto para a criação de um romance literário, ainda que a mídia e sua forma de pensar o sujeito tenha freqüentado as páginas de obras literárias de grande importância como no romance de Kozinski e em Mas não se matam cavalos?, de Horace McCoy (1982).

O romance de Toussaint é um bom exemplo de narrativa pós-moderna, a ação se encontra reduzida aos movimentos do personagem e à sua posição de espectador que narra a sucessão de eventos cotidianos que acontecem diante de si. No romance, sem grandes acontecimentos, se desenvolvem algumas situações cômicas que beiram o patético. De resto, o que o leitor

\footnotetext{
${ }^{3}$ Grifo nosso.
} 
encontra no desenrolar da narrativa é um exercício de crítica e do olhar, realizado pelo personagem narrador, que se realiza de forma apurada e, às vezes, de forma cínica e paródica.

A questão que permeia o romance de Toussaint é a do impasse criador no qual se encontra o narrador, motivado pela sua relação com a televisão ou pela falta de ligação que ele, deliberadamente, deixa de ter com ela. Narrado na primeira pessoa, o romance de Toussaint expõe a convivência que o narrador, um professor universitário, francês, em licença sabática, envolvido na realização de um estudo sobre o pintor renascentista, da escola veneziana, Ticiano Vecellio ${ }^{4}$, mantém com a televisão e sua decisão de deixar de assistir a sua programação, a fim de que possa dedicar o seu tempo à realização de seu projeto.

O narrador se encontra em Berlim, custeado por uma bolsa que recebera para escrever sobre Ticiano. Não é sua intenção produzir um ensaio sobre a obra do artista, mas refletir sobre as relações entre as artes e o poder político. Seu projeto se concentrou no século XVI, na Itália, mais particularmente sobre Ticiano Vecellio e Carlos V, até considerar como emblemático de seu estudo, dando-lhe o título de O Pincel, o episódio apócrifo do pincel segundo o qual Carlos V teria se abaixado no ateliê de Ticiano para apanhar um pincel que acabara de cair das mãos do pintor. É o inusitado da ação do Imperador que motiva o narrador a escrever sobre Ticiano.

A idéia central de seu trabalho é mostrar que o que há de extraordinário na anedota do pincel - que ele descobre narrada por Alfred de Musset (1810-1857) em sua novela Les Fils de Titien - não é tanto o fato de que o imperador tenha se abaixado para apanhá-lo, mas que Ticiano tenha deixado cair o pincel em presença do imperador. O gesto de Carlos V, abaixar para apanhar o pincel, expõe um reconhecimento, implícito, da preponderância da arte sobre o poder político.

Enquanto se prepara para dar início ao seu trabalho o narrador tece comentários teóricos acerca da televisão e sua força de penetração na vida cotidiana dos seus usuários. O que o romance de Toussaint traz de mais interessante é a narração da preparação para a realização do trabalho que o narrador elabora enquanto exerce, parodiando o Noveau Roman francês, a sua condição de observador que exercita o seu olhar cotidiano e narra não a sua experiência, mas a do outro (SANTIAGO, 1989).

\footnotetext{
${ }^{4}$ Ticiano Vecellio, 1488/90 - 1576
} 
A Televisão narra ainda as angústias que assaltam o intelectual no seu trabalho. Ainda que sejam angústias, no romance, elas são amenizadas por grandes momentos de reflexão e preparação que o narrador desfruta relaxando e exercitando o seu olhar de espectador sobrevoando a cidade de Berlim, nas piscinas públicas, ou sob o sol de verão dos parques públicos berlinenses, enquanto realiza o seu trabalho mental de organização do seu ensaio.

A Televisão é, ao mesmo tempo, um romance instigante e inquietante, devido à mistura de formas narrativas que ocorrem ao longo da sua escritura. Toussaint ora nos serve uma paródia do Noveau Roman francês, ora um ensaio sobre arte e política, ora um ensaio crítico-analítico sobre a televisão ou a apatia esmagadora que a grande cidade submete aqueles que nela habitam; tudo isso sem contar as cenas observadas pelo narrador que nos lembram passagens de alguns filmes clássicos - como Janela Indiscreta, onde o exercício do olhar é fundamental e dele pode depender a própria vida do observador.

\section{O FUTURO DA LITERATURA NA ERA DO DIGITAL}

Com a proximidade do final do século XX, e, conseqüentemente, a nossa entrada no século XXI, surgiram várias questões ligadas às transformações sociais e culturais que estão à espera de respostas satisfatórias acerca do que nos aguarda neste início de século. Tentar responder a essas questões de forma direta seria fazer um exercício divinatório, atitude, no mínimo, arriscada. Responder de uma forma que não seja direta não significa tentar escamotear-se do tema, mas levantar algumas questões importantes para o entendimento do que significa fazer e ler literatura nesse início de século.

O contexto das Novas Tecnologias Digitais, com destaque para o uso do computador, provoca uma nova postura do homem perante o mundo que se digitaliza a passos largos, ressalvados aqui os problemas econômicos que parecem insolúveis, gerados pelo capitalismo, um dos principais motores dessa transformação tecnológica e cultural que o mundo assiste literalmente ocorrer diante de seus olhos.

O computador e mais precisamente a rede mundial de computadores são os elementos de ponta dessa transformação, assim como foi a máquina de escrever no século XIX. A máquina de escrever, de certa forma, automatizou a escrita; o seu surgimento pôs o escritor numa nova relação com o texto, facilitando inclusive a leitura de originais. A máquina de escrever, assim como a roda, a luz elétrica, o cinema e o automóvel, é 
símbolo das transformações culturais e tecnológicas que acompanhavam o homem através dos séculos.

$\mathrm{Na}$ literatura brasileira do final do século XIX e início do século XX a transformação tecnológica seria não só bem vista por autores como João do Rio e Monteiro Lobato, como pela imprensa que começava a se modernizar. Enquanto autores como Lima Barreto viam o ato de datilografar originais como tarefa nauseante, outorgando, desta forma, à literatura a aura de trabalho artesanal e personalizada, Monteiro Lobato, um entusiasta da máquina datilográfica, escrevia no dia 22 de setembro de 1909, numa carta dirigida ao escritor Godofredo Rangel, insistindo com ele para que datilografasse os seus textos: "Que péssima letra tens - ainda pior que a minha! Precisamos arranjar máquinas de escrever" (SÜSSEKIND, 1987: 27).

Jorge Amado nunca aderiu à máquina de escrever elétrica, nunca abriu mão de sua máquina de escrever "dura", ou seja a máquina de escrever mecânica. "Ele habituou-se a ouvir o barulho das teclas", explica Zélia Gattai. "Uma vez lhe dei de presente uma elétrica, mas assim que encostou o dedo em uma das teclas e viu que ela disparou, deixou a máquina de lado". Quanto a sua relação com as novas tecnologias Zélia Gattai revela "Desde Crônica de uma namorada, 1995, escrevo meus livros por computador. Respeito essa máquina, ela não admite brincadeiras, qualquer erro pode colocar tudo a perder" (BORGES, 2001: 19) O escritor norte-americano Ray Bradbury, considerado o pai da realidade virtual por causa de seu conto The Veldt, sobre duas crianças que aprisionam os pais em um ambiente criado por computador, alimenta em relação ao uso de computadores para escrever aversão semelhante a que o escritor Lima Barreto nutria em relação à máquina datilográfica. Para Bradbury o computador é apenas o resultado da soma de outros artefatos tecnológicos como a máquina de escrever, do fax e do telefone em um só objeto. Na sua opinião ele já tem tudo isso e não necessita de computador (CALIL, 2001: 3), preferindo manter-se completamente "desplugado", numa típica reação tecnofóbica. Cada um em seu tempo constrói um discurso para evitar o uso ou o contato com a técnica, seja ela mecânica, elétrica ou digital.

A respeito do uso do computador Pierre Lévy escreve:

Se considerarmos o computador como uma ferramenta para produzir textos clássicos, ele será apenas um instrumento mais prático que a associação de uma máquina de escrever mecânica, uma fotocopiadora, uma tesoura e um tubo de cola. Um texto impresso em papel, embora produzido por computador, não tem estatuto ontológico nem propriedade estética fundamentalmente diferente 
dos de um texto redigido com instrumentos do século XIX. Pode-se dizer o mesmo de uma imagem ou de um filme feitos por computador e vistos sobre suportes clássicos. Mas se considerarmos o conjunto de todos os textos (de todas as imagens) que o leitor pode divulgar automaticamente interagindo com um computador a partir de uma matriz digital, penetramos num novo universo de criação e de leitura de signos.

Considerar o computador apenas como um instrumento a mais para produzir textos, sons ou imagens sobre um suporte fixo (papel, película, fita magnética) equivale a negar sua fecundidade propriamente cultural, ou seja, o aparecimento de novos gêneros ligados à interatividade (LEVI, 1996: 40-41).

Em alguns casos a "tecnofobia" pode ser um sintoma de problemas como baixa auto-estima e a dificuldade de relacionamento, que se manifestam em momentos em que a tecnologia se faz presente e necessária. A reação mais comum dos "tecnofóbicos" em face das suas incapacidades em operar com a técnica é a diminuição da importância do uso da tecnologia. Para que possam lidar com a própria inabilidade, algumas pessoas tendem a diminuir a habilidade que não dominam 5 . Este parece, guardadas as devidas proporções, ser o caso de Lima Barreto, Jorge Amado e Ray Bradbury.

Segundo os psicólogos Larry Rosen e Michelle Weil, ao começarem estudar a relação homem-máquina na década de 1980 as novas tecnologias figuravam como um evento mágico no imaginário da maioria das pessoas entrevistadas em suas pesquisas. Duas décadas depois esse cenários sofreu uma transformação radical. Os aceleradores de comunicação (MCLUHAN, 1995: 296): computadores, pagers, telefones celulares, correio eletrônico, Internet e uma imensa gama de artefatos surgidos com o avanço tecnológico digital se transformaram num fato concreto e indispensável para o dia-adia da maioria das pessoas. Porém, vários dos usuários atuais destas novas tecnologias - ou aspirantes - deixaram de lado a idéia de que elas seriam um sonho e passaram a vê-las como pesadelo, serrando fileiras numa nova categoria da neurose pós-moderna: os tecnofóbicos (BORGES, 2000: 16), parentes distantes dos luditas, grupo de operários ingleses que, no séc. XIX, se opunham à industrialização intensa ou às novas tecnologias, destruindo máquinas industriais, temendo o desemprego (SALE, 1999).

5 Rosa Maria Farah, psicóloga, integrante do Núcleo de Pesquisas da Psicologia em Informática da Pontifícia Universidade Católica (PUC-SP), citada in Borges, Robinson. "Tecnofobia". Jornal Valor Econômico, Caderno Eu \& O fim de semana. 2, 3,4 de março de 2001 - Ano I - Nº 44. P. 17. 
O cineasta alemão Wim Wenders, em pelo menos quatro de seus filmes, Hammett (1982), Até o fim do Mundo (1990), O Céu de Lisboa (1995) e O Fim da violência (1997), utiliza a imagem da máquina de escrever como ícone da essência e importância da palavra, no que para ele configura-se como uma árdua batalha entre as palavras e as imagens comercializadas via televisão. É possível identificarmos nesses filmes uma intensa valorização que Wenders faz da palavra escrita como mediadora das ações humanas.

Em Até o fim do mundo o narrador é um escritor que está escrevendo um romance chamado Até o fim do mundo. A história narrada no romance é a mesma que o espectador vê desenrolar-se na tela. Por conta de um acidente com um satélite nuclear indiano que explode na órbita da Terra, gerando uma pane eletromagnética no planeta, conseqüentemente, todos os artefatos eletroeletrônicos deixam de funcionar. Todos os dados armazenados nas memórias de computadores são perdidos, inclusive o romance que o narrador está escrevendo. Resta a ele, como última alternativa e recurso, para continuar o seu ofício de escritor, uma velha máquina de escrever Royal, que serve de brinquedo para um menino aborígine no deserto da Austrália. Com essa velha máquina o narrador escreve o seu romance que irá literalmente curar a principal personagem feminina do filme, Clair Tourneur, do vício das imagens, desenvolvido pelo uso de uma máquina de gravar sonhos e imagens retiradas diretamente do cérebro de quem a usa.

Em Hammett (BUCHKA, 1987) temos um escritor de histórias policiais, Dashiell Hammett, - a famosa Pulp Fiction, gênero literário norteamericano celebrado pelo cineasta americano Quentim Tarantino em seu filme de mesmo nome - em crise e um belíssimo começo de filme com uma seqüência de planos de uma máquina de escrever que é considerada plasticamente perfeita (SÜSSEKIND, 1987: 11). Em O céu de Lisboa encontramos um diretor de cinema em crise com seu filme sobre Lisboa, rodado numa velha câmera à manivela a dezesseis quadros por segundo, coletando, em vídeo, imagens não-selecionadas pelo olho humano, gravadas ao acaso pela cidade a partir de um roteiro composto com fragmentos da poesia de Fernando Pessoa. Nessa obra de Wenders todas as máquinas são antigas, pertencentes ao passado tecnológico do cinema, lugar onde o personagem do diretor de cinema, Friedrich Monroe, acredita ter ficado a inocência das imagens, as imagens que tinham alguma coisa para dizer e não para vender. Mais uma vez, Wenders faz o seu reforço sobre a importância da palavra ao evocar Fernando Pessoa e seus heterônimos para participarem no embate contra as imagens rasas, inconseqüentes e superficiais. 
Não é por acaso que em todos os seus filmes os aparelhos de televisão aparecem ligados, mas não há nada para ser visto neles, por isso não transmitem absolutamente nada. Em $O$ fim da violência a máquina de escrever reaparece nas mãos do velho pai de um cientista de computadores. Novamente a velha batalha entre palavras e imagem é travada, e caberá à palavra o papel de mediadora de todas os problemas e só por meio dela é possível encontrar uma saída para as nossas questões mais graves.

Literatura e técnica sempre estiveram aliadas. A própria difusão do texto impresso se deve a um artefato técnico, à invenção da imprensa por Gutenberg. No momento em que falamos tanto de crise de leitura e da palavra, em que as vanguardas chegaram a até mesmo negar a palavra, ela ressurge com mais força e vitalidade. A literatura tomou conta da rede mundial de computadores e do ciberespaço produzido por ela. A Internet é essencialmente um ambiente de divulgação e de circulação de idéias e conhecimento; no ciberespaço a literatura encontrou um suporte ideal para sua propagação, livre de intermediários e entraves de produção.

Isso não significa dizer que ao migrar para o ciberespaço a literatura esteja decretando a morte do livro (DERRIDA, 1973: 11-12). Não, esse é apenas mais um caminho para a difusão da palavra e da transformação dessa mesma palavra (TEMPO BRASILEIRO, 2000). A transição da escrita manual para a mecânica com o uso da máquina de escrever apontava para a agonia da imagem da literatura como atividade relacionada ao artesanal e altamente personalizada. A transição da escrita mecânica para a escrita virtual aponta para uma virtualização dos corpos e para a construção no ciberespaço daquilo que Pierre Lévi chama de Inteligência Coletiva, uma rede de cabeças pensantes que estão constantemente e silenciosamente transformando a realidade humana de forma planetária. Digo planetária (AXELOS, 1981) em lugar de globalizada, palavra que considero oca, sem sentido, assim como Otávio Paz definia outra palavra oca: modernidade (PAZ, 1982).

Quando se pensa no futuro da literatura em meio a tantas transformações tecnológicas se pensa imediatamente no fim do livro e esse é um grande equívoco, pois esses são dois finais ou, como queiram alguns, "duas mortes" que estão muito distantes. É possível afirmar que um dos futuros da literatura está no ciberespaço, que pode ser tomado como uma representação concreta do Aleph de Jorge Luís Borges, o escritor do virtual por excelência, ou qualquer um dos seus mundos imaginados, ou seja, um mundo com um futuro cheio de possibilidades. 
No filme O julgamento de Nuremberg (SIMONEAU, 2000) o arquiteto Albert Speer, após ouvir a sua sentença de condenação, é perguntado se tem algo à declarar, Speer põe-se de pé e faz um pequeno pronunciamento acerca do perigo que a tecnologia desenvolvida pela guerra trouxe, até aquele momento, e traria para a humanidade. Ele traça prognósticos sombrios que prevêem ameaças como mísseis controlados à distância e capazes de cruzar oceanos, indo de um continente a outro, dotados de alto poder de destruição. Jeffrey Herf avaliando a participação de Speer na elaboração de uma máquina de guerra tecnológica sem precedentes na história chega a seguinte conclusão:

Em suas memórias, Albert Speer alegou que seu erro foi o erro do artista e do arquiteto que permanecem desinteressados da política, do "tecnocrata apolítico" que faz o trabalho do diabo sem fazer perguntas inoportunas. Ministro de Armamentos de Hitler de 1942 a 1945, Speer criticou aqueles que, como ele mesmo, se preocupavam "com [seus] próprios afazeres, e tão pouco quanto possível com o que acontecia do lado de fora” (HERF, 1993:174-175).

Speer prevê ainda que o avanço tecnológico trará uma grande ameaça às liberdades individuais. $\mathrm{O}$ grande arquiteto nazista e do nazismo, um dos ideólogos da teoria do valor de ruína (HERF, 1993: 216-217), sabia do que falava, pois era um homem da técnica e sabia utilizá-la para o bem e para o mal. As suas previsões não estavam longe de se realizarem. Pois, anos mais tarde, com a polarização ocidente versus oriente protagonizada por Estados Unidos e União Soviética, começava outra guerra que levou a tecnologia a um avanço jamais imaginado.

\section{A CRÍTICA MODERNISTA E A CULTURA DAS TELAS}

O crítico norte-americano Harold Bloom (MOURA, 2001) argumenta sobre a permanência da "angústia da influência" dos jovens autores em relação às gerações já absorvidas pelo cânone. Para Bloom os autores contemporâneos ainda têm a necessidade de "matar" a geração anterior para que possa constituir-se enquanto renovação literária. Na visão de Bloom, esse caminhar por meio de um confronto direto com a produção da geração anterior deixaria de acontecer caso a literatura passasse por uma transformação radical, o que, na sua opinião, é muito difícil que ocorra. Como exemplo cita o caso do escritor português José Saramago. 
No seu modo de entender, Saramago estaria às voltas em uma competição com Eça de Queiroz e Fernando Pessoa, os grandes autores portugueses que o precederam. Bloom vê na explosão da ciberliteratura, ciberpoema e jogos verbais simples erupções tardias do que os Dadaístas e Surrealistas fizeram há 100 anos. Este é um posicionamento contraditório e parece esquecer o caráter histórico que toda criação poética carrega naturalmente consigo, o fato de todo poema ser a manifestação do desejo de negar a sucessão e estabelecer um reino perdurável.

É possível concordar com Bloom no que dizrespeitoà literatura produzida para a rede internacional de computadores, pois ainda não surgiram autores que utilizem este suporte tecnológico de forma convincente, porém discordamos da sua visão de que a cibercultura personificada pela Internet impedirá o surgimento de um novo Fernando Pessoa (CALIL, 2000: 3). Pensar que de tempos em tempos surge um novo luminar da literatura mundial cuja produção literária está ancorada ou representa a retomada de um grande autor já considerado clássico é um grande equivoco do crítico de Yale. Pois, de forma alguma, haverá um outro Pessoa, assim como não haverá outro Kafka, Joyce, Guimarães Rosa ou Machado de Assis. Ainda que clonássemos o poeta português - deixando de lado todas as discussões éticas que esse ato geraria - utilizando amostras do seu DNA, e isso já não é mais uma fantasia da literatura de ficção científica ou do cinema, nada garantiria que o clone pessoano viesse a desenvolver as habilidades poéticas da sua matriz.

A diatribe de Bloom contra a cultura da tela revela uma incapacidade sua para o reconhecimento de que a cultura literária há muito tempo deixou de ser o único meio de aquisição de conhecimento, antes mesmo do advento das tecnologias automatizadas. Marshall McLuham (2000) chamou a atenção para esse fato e mais recentemente o filósofo Peter Sloterdijk (2000: 14). A Internet não é o grande vilão que põe a literatura em risco como quer Bloom, assim como toda a cultura da tela apontada por ele, e aí estão incluídos o cinema, o computador e a televisão. Estes são meios que, de uma forma ou de outra, estão, de tempos em tempos, recuperando para a tela autores clássicos da literatura universal. Levando para o público um pouco mais do que textos - na acepção barthesiana do termo, ou seja, do objeto que é passível de leitura por ser portador de um discurso - para leitores de doze anos (STEINER, 1988), tenha o público doze ou oitenta anos.

Os comentários de Bloom denotam claramente uma acomodação crítica em relação ao novo, pois, de certa forma, não há nada mais "cômodo" do 
que falar do já consagrado e canônico, supostamente não dá trabalho e o risco de cometer erros de avaliação e de prognóstico é infinitamente menor. Cremos ser bastante adequado à postura de Bloom, acerca do que o leitor deva ler, o aforismo de Oscar Wilde "É um absurdo que alguém tenha uma regra rígida e imutável para aquilo que deve ou não deve ler. Mais da metade da cultura moderna depende daquilo que a pessoa não deveria ler" (WILDE, 1995).

Ortega y Gasset em seu magistral ensaio teórico, A Desumanização da Arte (1991: 84), ao comentar os movimentos de vanguarda do início do século XX, que compuseram o Modernismo, chega à conclusão, que uma leitura apressada nos levaria a crer que seu posicionamento em relação ao novo movimento artístico que está se desenvolvendo seja semelhante à posição em que se colocou Harold Bloom. Porém, o crítico espanhol adota uma postura generosa e se coloca em estado de espera em relação ao que designava pelo nome de nova arte e ao que ela poderia vir a produzir:

Dir-se-á que a nova arte não produziu até agora nada que valha a pena, e eu estou muito próximo de pensar o mesmo. Das obras jovens procurei extrair sua intenção, que é substancioso, e não me preocupei com sua realização. Quem sabe o que dará esse nascente estilo? A empresa que acomete é fabulosa - quer criar do nada. Eu espero que mais adiante se contente com menos e acerte mais (ORTEGA Y GASSET, 1991: 84).

A possibilidade de que uma nova literatura esteja em gestação sob o manto das novas tecnologias perturba as sensibilidades menos atuais. Pensar que a ciberliteratura, a música, a ciberarte é pura "farsa" - no mau sentido da palavra - é não admitir que alguém veja na farsa a missão radical da arte. A "farsa" se instauraria se o artista pós-moderno se lançasse numa concorrência com arte "séria" do passado, e as obras produzidas por essa arte exigissem o mesmo tipo de culto que era devotado a obra de arte antes da reprodutibilidade técnica. No modernismo o artista convidava o espectador a contemplar uma arte que era um chiste, que era, essencialmente, a mofa de si mesma. No pós-modernismo, recorrentemente considerado um pastiche (JAMESON, 1996), a arte convida para uma contemplação da reorganização dos signos da cultura que estruturam e compõem a arte pósmoderna (LIMA, 1998: 143).

Umberto Eco observa que há na relação entre literatura e tecnologia novas possibilidades de leitura do texto literário. Eco reforça a permanência das obras clássicas como valores fundamentais. A literatura faz parte de 
um conjunto de poderes imateriais, cujo peso não se pode medir, mas ainda pesam, e não estão restritos aos chamados valores espirituais, como os das doutrinas religiosas. Como exemplo, temos o poder imaterial das raízes quadradas, cujas leis resistem aos séculos e aos decretos de tiranos e ditadores e até mesmo às determinações do papa. Entre esses poderes incluiríamos o da tradição literatura, isto é, da totalidade de textos que a humanidade produziu e produz, não com objetivos funcionais, mas gratia sui, por amor a si mesma, e que são lidos por prazer, elevação espiritual ou para ampliar os conhecimentos (ECO, 2001).

\section{REFERÊNCIAS BIBLIOGRÁFICAS}

ALENCAR, José. Iracema: lenda do Ceará. São Paulo: Ática, 1992.

AXELOS, Kostas. "O futuro da técnica". Tradução Célia Maria de Albuquerque Portella. In Signos da técnica. Rio de janeiro: Revista Tempo Brasileiro, setembro - dezembro, $\mathrm{n}^{\circ}$ 67, 1981.

BARTHES, Roland. O grão da voz: entrevistas 1962-1980. Lisboa: Edições 70, 1982. (Coleção Signos, 37).

BENJAMIN, Walter. "Sobre o conceito da história" in Benjamin, Walter. Magia e técnica, arte e política: Ensaios sobre literatura e história da cultura. Tradução: Sérgio Paulo Rouanet. Prefácio: Jeanne Marie Gagnebin. $4^{\mathrm{a}}$ ed. São Paulo: Brasiliense, 1985.

BORGES, Robinson. "Tecnofobia". Jornal Valor Econômico, Caderno Eu \& O fim de semana. 2, 3,4 de março de 2001 - Ano I - No 44.

BOUDIEU, Pierre. Sobre a televisão. Seguido de: a influência do jornalismo e os jogos olímpicos. Tradução Maria Lucia Machado. Rio de Janeiro: Jorge Zahar Editor, 1997.

BUCHKA, Peter. Os olhos não se compram: Wim Wenders e seus filmes. Tradução Lúcia Nagib. São Paulo: Companhia das Letras, 1987.

CALIL, Ricardo. Ode à literatura na era do visual. Jornal Gazeta Mercantil, caderno fim de semana, 19, 20, 21 de maio de 2000.

Ficção científica acima da ciência. Jornal Gazeta Mercantil, caderno fim de semana, 9, 10, 11 de fevereiro de 2001. 
CALVINO, Ítalo. Por que ler os clássicos. Tradução Nilson Moulin. $6^{\mathrm{a}}$ reimpressão. São Paulo: Companhia das Letras, 2000.

Letras, 1998.

CANCLINI, Nestor Garcia. Consumidores e Cidadãos: conflitos multiculturais da globalização. Rio de Janeiro: Editora UFRJ, 1997.

DERRIDA, Jacques."O fim do livro e o começo da escritura" in gramatologia. Tradução Miriam Schnaiderman e Renato Janine Ribeiro. São Paulo: Editora da Universidade de São Paulo/Editora Perspectiva, 1973.

EAGLETON, Terry. A função da crítica. São Paulo: Martins Fontes, 1991.

ECO, Umberto. A literatura contra o efêmero. Tradução Sérgio Molina. São Paulo: Jornal Folha de São Paulo Mais! 18 de fevereiro de 2001.

FAWCETT, Fausto. Santa Clara Poltergeist. Rio de Janeiro: Editora Eco, sd. FONSECA, Rubem. Romance Negro e outras histórias. São Paulo: Companhia da Letras, 1992.

HERF, Jeffrey. "Os engenheiros como ideólogos" in Modernismo reacionário: tecnologia, cultura e política na República de Weimar e no $3^{\circ}$ Reich. São Paulo: Ensaios. Campinas, SP: Editora Universidade Estadual de Campinas, 1993. (Estante do Pensamento Crítico).

JAMES, Henry. A arte da ficção. Seleção e organização Antônio Paulo Graça. Tradução Daniel Piza. São Paulo: Editora Imaginário, 1995.

JAMESON, Fredric. Pós-modernismo: a lógica cultural do capitalismo tardio. Tradução Maria Elisa Cevasco. São Paulo: Editora Ática, 1996.

KOZINSKI, Jerzy. O videota.Tradução Hindemburgo Dobal. Rio de Janeiro: Artenova, 1971.

LÉVY, Pierre. O que é o virtual. Tradução Paulo Neves. São Paulo: Ed. 34, 1996. (Coleção Trans)

LIMA, Luiz Costa. "Quem tem medo da teoria" In Dispersa demanda: ensaios sobre literatura e teoria. Rio de Janeiro: Francisco Alves, 1981. 
LIMA, Rogério. O dado e o óbvio: a significação do romance na pósmodernidade. Brasília: Editora Universidade de Brasília/Universa, 1998.

MCCOY, Horace. Mas não se mata cavalo? Tradução Érico Veríssmo. São Paulo: Abril Cultural, 1982. (Grandes Sucessos)

MCLUHAN, Marshall. Os meios de comunicação como extensões do homem (understanding media). São Paulo: Cultrix, 1995.

"Visão, som e fúria" in Adorno et ali.Teoria da cultura de massa. $5^{a}$ Edição. Introdução, comentários e seleção de Luiz Costa Lima. São Paulo: Paz e Terra, 2000.

MERQUIOR, José Guilherme. Arte e sociedade em Marcuse, Adorno e Benjamin: ensaio crítico sobre a escola neo hegeliana de Frankfurt. Rio de Janeiro: Tempo Brasileiro, 1969.

MOURA, Flávio. Leio, Logo existo.Veja on line. Entrevista Harold Bloom. São Paulo: Abril, edição 1685, 31 de janeiro, 2001. http://www2.uol.com. br/veja/310101/entrevista.html

ORTEGA Y GASSET, José. A desumanização da arte. Tradução Ricardo Araújo. São Paulo: Cortez Editora, 1991.

PAZ, Octavio. O arco e a lira. Tradução Olga Savary, 2 ed. Rio de Janeiro: Nova Fronteira, 1982.

PÉCORA, Alcir. Milênio para iniciantes: literatura. São Paulo: Folha de São Paulo Mais!, 31 de dezembro de 2000.

PERRONE-MOISÉS, Leyla. Que fim levou a crítica literária? São Paulo: Jornal Folha de São Paulo Mais! 25 de agosto de 1996.

POE, Edgar Allan. Histórias Extraordinárias. Tradução Brenno Silveira e outros. São Paulo: Abril Cultural, 1981.

POE, Edgar Allan. Manuscrito encontrado numa garrafa e outros contos. Tradução Oscar Mendes e Milton Amado, seleção de textos Maura Sardinha. Rio de Janeiro: Ediouro, 1996. 
PORTELLA, Eduardo. "O ensaio como ensaio" In Literatura Brasileira depois das utopias. Revista Tempo Brasileiro, abril-junho - $\mathrm{n}^{\circ}$ 141- 2000 - Rio de Janeiro, Tempo Brasileiro.

ROUANET, Sérgio PauloAs razões do iluminismo. São Paulo: Companhia das Letras, 1989.

SALE, Kirkpatrick. Inimigos do futuro: a guerra dos luditas contra a revolução industrial e o desemprego: lições para o presente. Tradução Valéria Rodrigues. Rio de Janeiro: Record, 1999.

SANTIAGO, Silviano. "O narrador pós-moderno" in Nas malhas da letra: ensaios. São Paulo: Companhia das Letras. 1989.

SLOTERDIJK, Peter. Regras para o parque humano. Uma resposta à carta de Heidegger sobre o humanismo. Tradução José Oscar de Almeida Marques. São Paulo: Estação Liberdade, 2000.

STEINER, Jorge. Linguagem e silêncio: ensaios sobre a crise da palavra. Tradução Gilda Stuart e Felipe Rajabally. São Paulo: Companhia das Letras, 1988.

SUBIRATS, Eduardo. Da vanguarda ao pós-moderno. 4a ed. São Paulo: Nobel, 1991.

SÜSSEKIND, Flora. Cinematógrafo das letras: literatura, técnica e modernização no Brasil. São Paulo: Companhia das Letras, 1987.

TALENS, Jenaro. Escritura contar o simulacro: el lugar de la literatura en la era electrónica. Valencia: Centro de Semiótica y Teoria del espetáculo, Universitat de Valencia \& Asociación Vasca de Semiótica. EUTOPÍAS, $2^{\mathrm{a}}$ época, Documentos de trabajo, Vol. 56, 1994.

TEMPO BRASILEIRO. “O lugar do livro hoje”. Revista Tempo Brasileiro, julho - setembro - $\mathrm{n}^{\circ}$ 142. Rio de Janeiro: Tempo Brasileiro, 2000.

TOUSSANT, Jean-Philippe. A televisão. São Paulo: Editora 34, 1999.

XAVIER. Valêncio. O mez da gripe e outros livros. São Paulo: Companhia das Letras, 1998. 
WILDE, Oscar. Aforismos. Introdução Ricardo Reim. Tradução de Mario Fondelli. Rio de Janeiro: Newton Compton Brasil Ltda, 1995. (Clássicos Econômicos Newton)

\section{REFERÊNCIAS FILMOGRÁFICAS}

SIMONEAU, Yves. Nuremberg, EUA: Warner Home Video, 2000.

WENDERS, Wim. Hammett. $35 \mathrm{~mm}$, Technicolor, 94 minutos. Produção: Fred Ross, Ronald Colby, Don Guest. Produtor Executivo Francis Ford Coppola. Elenco: Frederic Forrest (Hammett), Peter Boyle (Jimmy Ryan), Marilu Henner, Roy Kinnear, Elisha Cook, Lydia Lei, R. G. Armstrong, Richard Bradford, Michael Chow, Sylvia Sidney, Samuel Fuller, David Patrick Kelly, Jack Nance, Elmer L. Kline, Royal Dano, Lloyd Kino, Fox Harris, Rose Wong, Liz Roberson, Jean François Ferreol, Alison Hong, Hank Worden. 1982.

Até o fim do mundo. Majestic Films. Produção: Jonathan

Taplin e Anatole Dauman. Distribuidor: Top Tap Home Vídeo. Willian Hurt - Solveig Dommartin - Sam Neill - Max Von Sydow - Rüdiger Vogler - Ernie Dingo - Jean Moreau - Fotografia: Robby Müller. Música: Graeme Revell. Edição: Peter Przygodda. 1990.

. O céu de Lisboa. Madragoa Filmes. Jõao Canijo. Produção: Ulrich Felsberg e Paulo Branco. Distribuidor: Top Tape. Rüdigler Vogler - Patrick Bauchau - Teresa Salgueiro e Madredeus. Fotografia: Lisa Rinzler. Edição: Peter Przygodda e Ane Schinee. Direção de Arte: Zé Branco. Música: Madredeus. Road Movies Films, Berlim, 1995.

. Ofim da violência. Ciby 2000. Co-produção 2Ciby Pictures/ Road Movies Kintop Filmes. Wim Wenders. Elenco: Bill Pullman, Andie MacDowell, Gabriel Byrne, Loren Dean, Tracy Lind, Pruitt TaylorVince. Elenco: Heidi Levitt. Supervisão Musical: Sharon Boyle. Música: Ry Cooder. Edição Peter Przygodda. Desenhista de Produção Patrícia Norris. Direção de Fotografia: Pascal Rabaud. Produzido por: Deepak Nayar, Wim Wenders, Nicholas Klein. Produtores Executivos: JeanFrançois Fonlupt, Ulrich Felsberg. História de Nicholas Klein e Wim Wenders. Escrito por: Nicholas Klein. 1997. Distribuido em cinema no Brasil por Columbia Tristar Films of Brasil Inc. \& Playart Pictures. 